\title{
Detection and Live-Cell Imaging of a Micro-RNA Associated with the Cancer Neuroblastoma
}

\author{
Eoin Brennan, Roisin Moriarty, Tia E Keyes and Robert J. Forster* \\ School of Chemical Sciences, \\ Dublin City University, \\ Dublin 9, Ireland
}

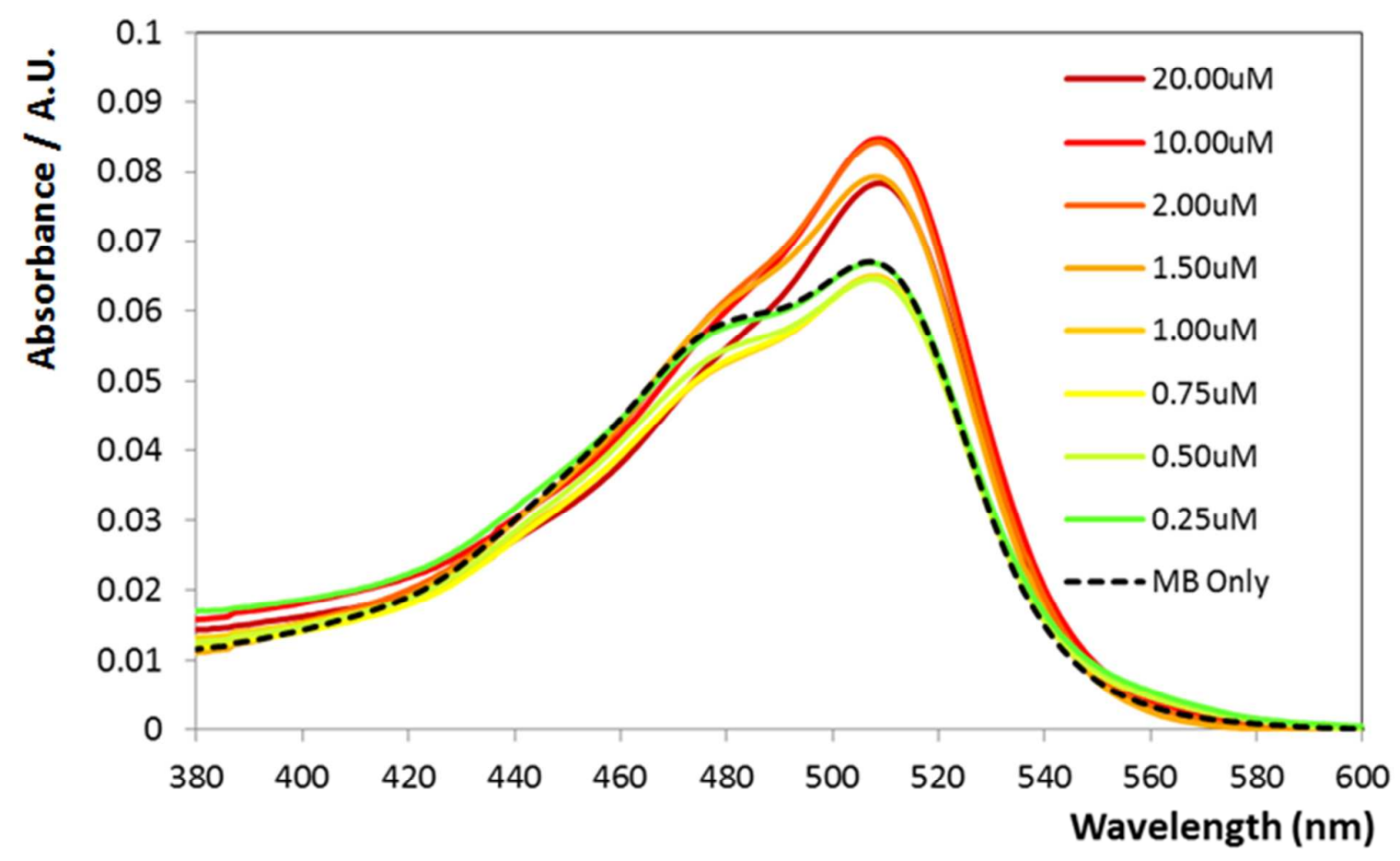

Figure S1: Absorption spectra of $1 \mu \mathrm{M}$ molecular beacon in PBS in the absence of target (- - ), and $1 \mu \mathrm{M}$ molecular beacon in PBS with varying concentration of miRNA-132 between $0.25 \mu \mathrm{M}$ and $20 \mu M$, after a hybridisation time of 10 minutes. 


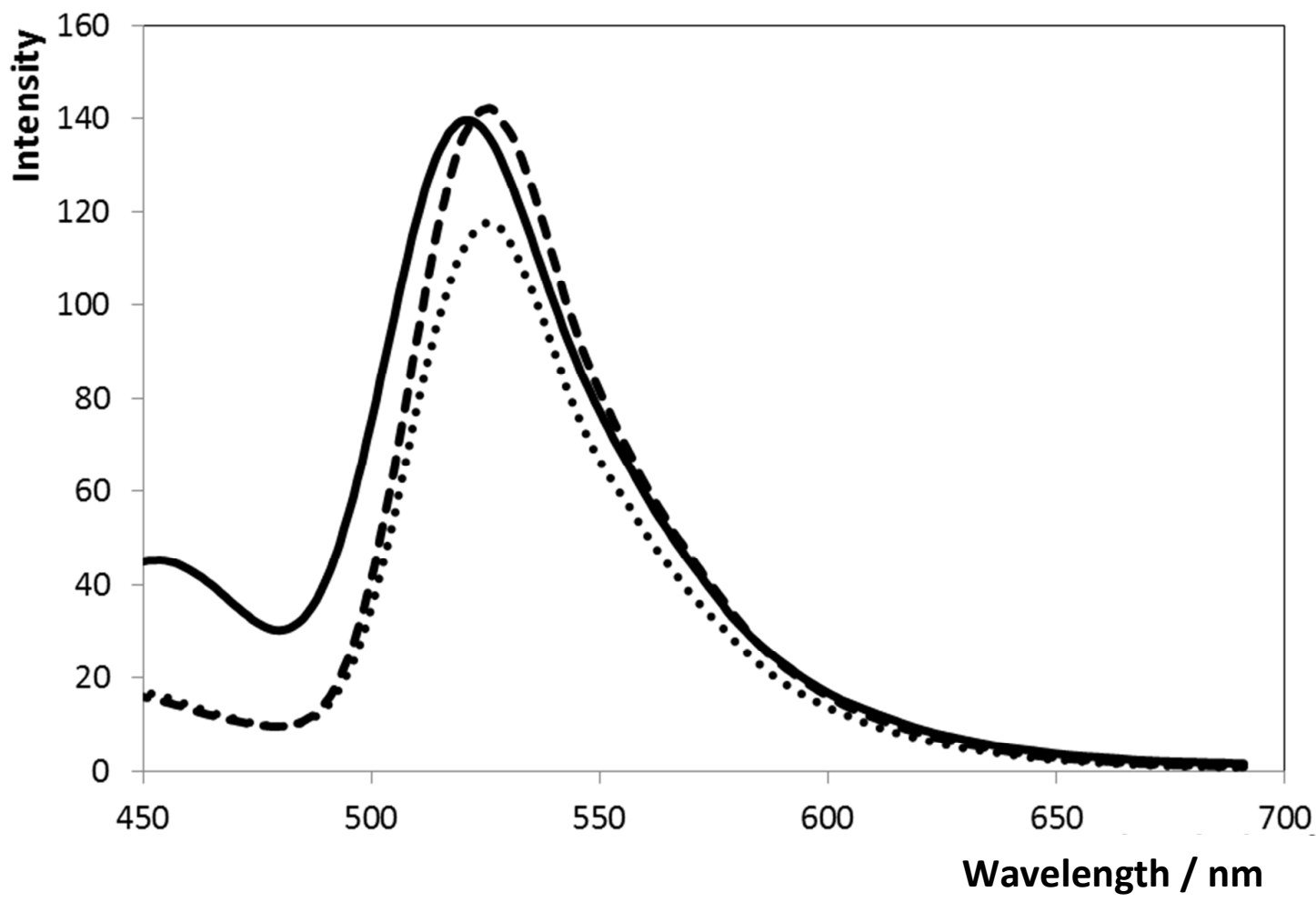

Figure S2: Emission spectra of $1 \mu \mathrm{M}$ molecular beacon in PBS in the absence of target (-), and $1 \mu \mathrm{M}$ molecular beacon in PBS with $1 \mu \mathrm{M} 1$ Base mismatch (...) and $1 \mu \mathrm{M} 2$ Base mismatch (- - -), after a hybridisation time of 10 minutes. 


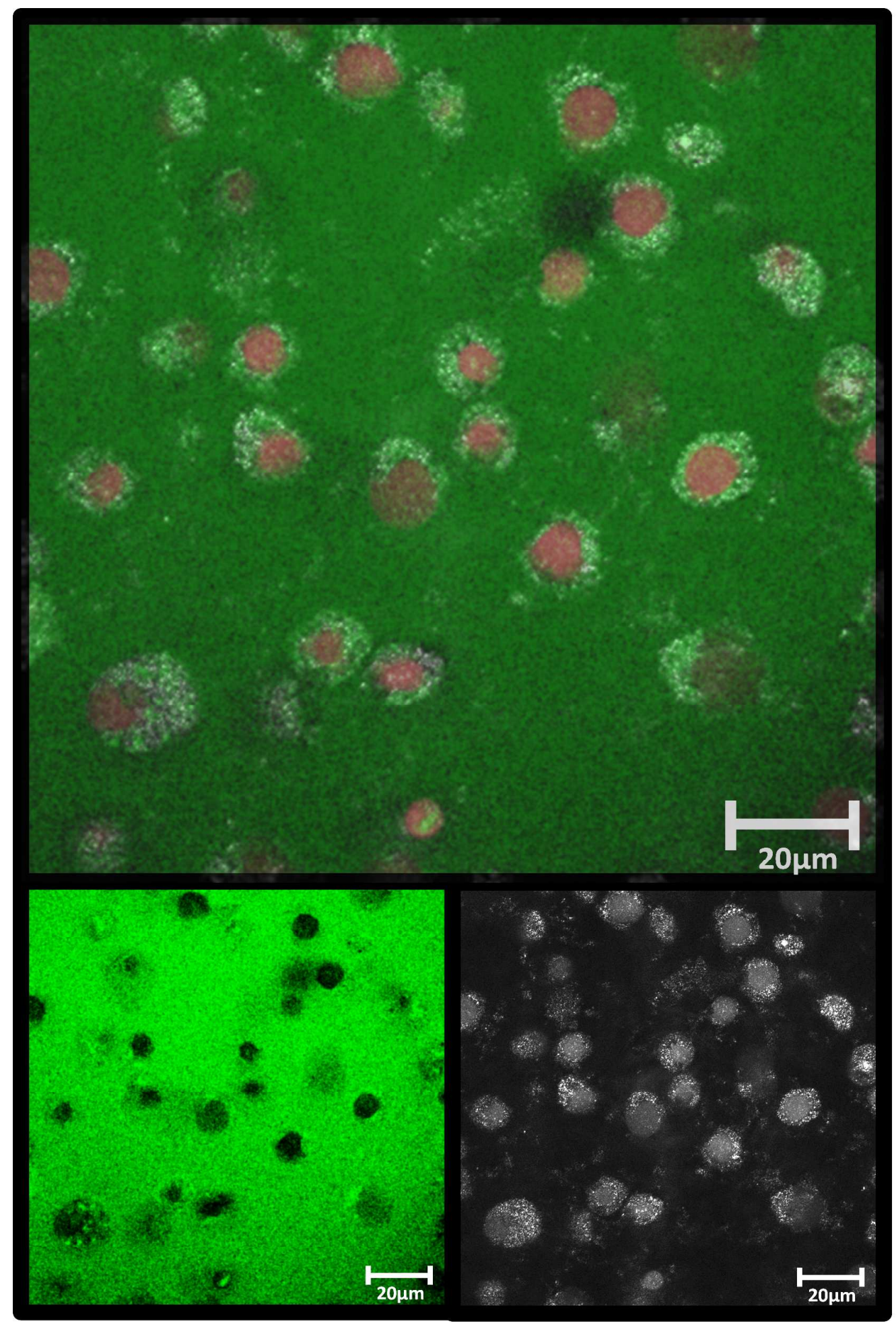

Figure S3: Confocal image of floating SK-N-AS cells 24 hours after electroporation with $50 \mu M$ 6-FAM (Green) in PBS and with $1 \mu M$ DRAQ7 (Red) viability dye. Excitation with argon ion laser at 458nm and with an LP560 filter at $6 \%$. 